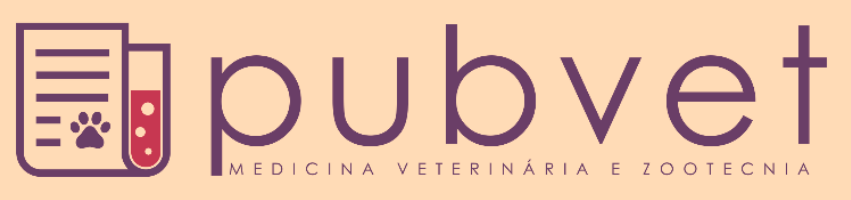

ISSN $1982-1263$

https://doi.org/10.31533/pubvet.v14n9a648.1-6

\title{
Pesquisa de Salmonella spp. em mussarela na cidade de Belo Horizonte
}

\author{
Daniele Cristine de Oliveira Freitas ${ }^{1 *} \bullet$, Matheus Antônio Resende ${ }^{1} \bullet$, Priscila Moreira de \\ Carvalho $^{1} \bullet$, Ruitter Damião Ramos $^{2}$, Fernanda Meneghello Delvivo Fortes ${ }^{3} \bullet$, Breno Mourão \\ de $\operatorname{Sousa}^{4}{ }^{\circ}$
}

\author{
${ }^{1}$ Acadêmico do Curso de Medicina Veterinária, bolsista de iniciação científica do Centro Universitário de Belo Horizonte, Instituto de \\ ciência biológicas e da saúde-ICBS. Belo Horizonte-MG Brasil. \\ ${ }^{2}$ Acadêmico do Curso de Farmácia do Centro Universitário UNA. Belo Horizonte-MG Brasil. \\ ${ }^{3}$ Professora do Centro Universitário UNA. Belo Horizonte-MG Brasil. \\ ${ }^{4}$ Professor do Centro Universitário de Belo Horizonte, Instituto de ciência biológicas e da saúde - ICBS. Belo Horizonte-MG Brasil. \\ *Autor para correspondência, E-mail:danieleoliveira.dcof@gmail.com
}

Resumo. As bactérias do gênero Salmonella são patógenos causadores da salmonelose em humanos, uma infecção alimentar provocada pelo consumo de alimentos contaminados pela bactéria, isto pode ocorrer pela ausência de práticas de higiene no processo de produção do leite, refrigeração inexistente ou feita incorretamente, ausência de processos térmicos ou feito de forma inadequada, mão de obra desqualificada além disso podem estar presentes em superfícies mal higienizadas que entram em contato com o alimento. Como estas situações são comumente encontradas em pequenas e médias propriedades rurais, objetivou-se nessa pesquisa analisar a presença de Salmonella spp. em queijo tipo Mussarela sob diferentes tipos de processamento, comercializados no varejo da região metropolitana de Belo Horizonte, além de avaliar a influência da tecnologia de fabricação na identidade e qualidade do queijo em questão, como forma de garantir a saúde e o bem-estar da população humana potencialmente consumidora.

Palavras chave: mussarela, salmonelose, salmonela em queijo Mussarela, análise de alimentos

\section{Research of Salmonella spp. in mozzarella in the city of Belo Horizonte}

Abstract. Bacteria of the genus Salmonella are pathogens that cause salmonellosis in
humans, a food infection caused by the consumption of food contaminated by the
bacteria, this can occur due to the absence of hygiene practices in the milk production
process, non-existent or improper refrigeration, absence of processes thermal or
improperly, unqualified labor may also be present on poorly sanitized surfaces that come
into contact with food. As these situations are commonly found in small and medium
rural properties, the objective of this research was to analyze the presence of Salmonella
spp. in Mozzarella cheese under different types of processing, sold in the retail area of the
metropolitan region of Belo Horizonte, in addition to assessing the influence of
manufacturing technology on the identity and quality of the cheese in question, as a way
of guaranteeing the health and well-being of the potentially consuming human
population.

Keywords: mozzarella, salmonellosis, salmonella in cheese Mozzarella, food analysis 


\section{Investigación de Salmonella spp. en mozzarella en la ciudad de Belo Horizonte}

Resumen. Las bacterias del género Salmonella son patógenos que causan salmonelosis en humanos, una infección alimentaria causada por el consumo de alimentos contaminados por la bacteria, esto puede ocurrir debido a la ausencia de prácticas de higiene en el proceso de producción de leche, refrigeración inexistente o inadecuada, ausencia de procesos térmicos o inadecuadamente, el trabajo no calificado también puede estar presente en superficies mal desinfectadas que entran en contacto con los alimentos. Como estas situaciones se encuentran comúnmente en propiedades rurales pequeñas y medianas, el objetivo de esta investigación fue analizar la presencia de Salmonella spp. en queso Mozzarella bajo diferentes tipos de procesamiento, vendido en el área minorista de la región metropolitana de Belo Horizonte, además de evaluar la influencia de la tecnología de fabricación en la identidad y calidad del queso en cuestión, como una forma de garantizar la salud y el bienestar de población humana potencialmente consumidora.

Palabras clave: mozzarella, salmonelosis, salmonella en queso mozzarella, análisis de alimentos

\section{Introdução}

A indústria queijeira brasileira representa um importante segmento do setor lácteo (Spilotro, 2003; Teixeira \& Fonseca, 2008). Em 2011 a Associação Brasileira das Indústria de Queijo - ABIQ estimou que a produção brasileira de queijo chegou a 745 mil toneladas (ABIQ, 2011). Segundo Martins (2001), o estado de Minas Gerais produzia cerca de 215 mil toneladas de queijo por ano, o que equivale a $50 \%$ da produção nacional. Com faturamento em média 5,5 bilhões de reais/ano e consumo de 2,3 quilos per capita ao ano. De acordo com dados da ABIQ, o consumo de queijo passou de $3,5 \mathrm{~kg}$ per capita em 2008 para 5,0 kg em 2014. Em conformidade com o desempenho nacional, a produção e o consumo de queijos em Minas Gerais cresceram a um ritmo de $8 \%$ ao ano nos últimos cinco anos até 2014 (ABIQ, 2014).

Os problemas de higiene no manejo de ordenha, limpeza inadequada dos equipamentos utilizados, refrigeração inexistente ou feita incorretamente, ausência de processos térmicos ou feito de forma inadequada, além da mão de obra desqualificada, são situações comumente encontradas em pequenas e médias propriedades rurais (Vallin et al., 2009). Essas falhas que ocorrem no sistema de produção possuem como principais consequências queda brusca na produção animal, além de uma matéria prima de baixa qualidade devido a contaminação do produto, que ocorre em todas as etapas de produção. Como consequência, o produtor apresenta uma perda na produção, além de problemas na saúde dos animais, e começa a ter prejuízos financeiros, o que pode levar a sua possível saída da atividade leiteira ou sua entrada na informalidade (Santos \& Lirio, 2014).

Diante desse cenário, que visa uma melhoria em busca da excelência em qualidade, o Ministério da Agricultura, Pecuária e Abastecimento (MAPA), publicou a instrução normativa $\mathrm{n}^{\circ} 62$ (IN62) em 2011, que visa a análise de ações focadas na melhoria da qualidade do leite no Brasil, enfatizando a forma correta de produção do leite, desde a ordenha até seu destino final, além de estabelecer valores limitantes para as composições físico-químicas (proteína, gordura, acidez titulável, extrato seco e índice crioscópico) e microbiológicas (contagem de células somáticas, contagem bacteriana total de um leite de qualidade) (Brasil, 2011).

Com base na IN62, utiliza-se como indicativos para avaliar a qualidade microbiológica do leite, as análises de CCS e CBT, onde os estados do Sul, Sudeste e Centro-oeste a partir de primeiro de julho de 2019, não podem ultrapassar de $500.000 \mathrm{UFC} / \mathrm{mL}$ para CBT e 400.000 Céls/ml para CCS (IN62, 2011). Se o leite apresenta esses valores acima do que é requisitado pelo MAPA, indica, no caso da CBT, uma má qualidade e higiene da ordenha e em relação a CCS aponta que a saúde do rebanho está comprometida, devido a presença de mastite (Matsubara et al., 2011), processo inflamatório da glândula mamária da vaca (Freitas et al., 2005; Silva, 2012).

As bactérias do gênero Salmonella são bactérias mesófilas, sendo alguns sorotipos psicrotróficos. Este patógeno causa a salmonelose em humanos, uma infecção alimentar provocada pelo consumo de 
alimentos contaminados pela bactéria, isto pode ocorrer pela ausência de práticas de higiene no processo de produção do leite e no seu armazenamento inadequado e podem estar presentes em superfícies mal higienizadas que entram em contato com o alimento (Birgel et al., 2009).

Nesse contexto o objetivo da pesquisa foi analisar a presença de Salmonella spp. em queijo tipo Mussarela sob diferentes tipos de processamento, comercializados no varejo da região metropolitana de Belo Horizonte, além de avaliar a influência da tecnologia de fabricação na identidade e qualidade do queijo em questão, como forma de garantir a saúde e o bem-estar da população humana potencialmente consumidora.

\section{Material e métodos}

\section{Região de coleta de amostras}

As amostras de queijo na região de Belo Horizonte foram procedidas diretamente na rede de varejo de doze bairros selecionados das regionais Leste, Norte, Oeste e Sul. A saber: Regional Leste (Taquaril; Santa Efigênia; Centro; Sagrada Família), regional Norte (Venda Nova; Céu Azul; Planalto), regional Oeste (Pampulha; Coração Eucarístico; Caiçara), regional Sul (Buritis; Barreiro; Mangabeiras).

\section{Coleta de amostras}

Nas coletas das amostras em cada um dos doze bairros foram randomicamente selecionados dois estabelecimentos comerciais autorizados para amostragem de 200 gramas de queijo tipo Mussarela manipulados em varejo (fatiado) e 200 gramas de queijo tipo Mussarela original de fábrica (proveniente de mesma origem fabril), totalizando duas amostras por estabelecimento e quatro amostras em cada um dos bairros. As amostragens foram feitas entre os dias 21 de setembro e 15 de outubro de 2019 e entre 23 de novembro e 3 de dezembro do mesmo ano.

Após amostragem, todo material em embalagens originais foram imediatamente refrigerados em caixas de isopor com gelo reciclável e em menos de três horas após a coleta, as amostras foram congeladas em freezer $\left(-4^{\circ} \mathrm{C}\right)$ até que fossem e encaminhadas para o Laboratório de Referência do Centro Universitário UNA - Campus Guajajaras para o processamento e análises de presença de Salmonella spp., em menos de quinze dias transcorridos da data inicial de coleta. No laboratório de análise, as amostras foram descongeladas em temperatura ambiente e processadas para pesquisa de Salmonella spp. Todos os procedimentos descritos foram realizados entre os dias 21 de setembro de 2018 e 7 de dezembro do mesmo ano, sendo um total de duas réplicas por amostra.

\section{Análises microbiológicas}

Ao todo, noventa e seis amostras de queijo tipo Mussarela foram analisadas de acordo com os Métodos Analíticos Oficiais para Análises Microbiológicas para controle de produtos de origem animal e água (BRASIL, 2003).

As amostras foram submetidas às análises microbiológicas exigidas pela $\operatorname{RDC} \mathrm{n}^{\circ} 12$, de 2 de janeiro de 2001 do Ministério da Saúde e Portaria $\mathrm{n}^{\circ} 146$ de 07 de março de 1996 do Ministério da Agricultura, utilizando o Laboratório de Referência da UNA, Campus Guajajaras.

Foi realizado os seguintes procedimentos para as análises microbiológicas das amostras, baseado em fluxograma do referido laboratório: Primeiramente em tubos estéreos identificados com o número de cada amostras foi feito o pré-enriquecimento, na qual utilizou-se $10 \mathrm{~g}$ da Mussarela, diluída em 90 $\mathrm{mL}$ de água tamponada e incubado por 24 horas à $37^{\circ} \mathrm{C}$. Em seguida, na etapa do enriquecimento seletivo, volume de $1000 \mu \mathrm{L}$ foi transferido para dois diferentes meios de enriquecimento, Rappaport Vassilidis (RV) e caldo tetrationato (TT), e incubados por 24 horas em $37^{\circ} \mathrm{C}$. Após este procedimento, na etapa de plaqueamento seletivo diferencial, fez-se as estrias em meio de cultura Ágar Xilose Lisina Desoxicolato (XLD) e Ágar entérico de Hektoen (HE), onde foram incubados, durante 24 horas à $37^{\circ} \mathrm{C}$. Por fim as colônias típicas foram perfuradas e estriadas em Ágar Tríplice Açúcar Ferro (TSI), e posteriormente os crescimentos típicos foram replicados em meio SIM. 


\section{Análise estatística}

Os resultados das análises foram comparados com os padrões exigidos pelo Ministério da Agricultura para amostras coletadas na fonte de produção (Brasil, 1996). Os resultados das amostras coletadas nos pontos de origem e de comercialização foram comparados com os padrões da portaria 364/1997para queijos tipo Mussarela e com a Instrução Normativa No 83 - IN83/2003 (Brasil, 2003).

\section{Resultados e discussão}

Tabela 1. Frequências absolutas e relativas (\%) para casos positivos de pesquisa de Salmonella spp. queijo tipo Mussarela comprada sob diferentes tipos de processamento, original de fábrica ou manipulado pelo varejo de quatro regionais da região metropolitana de Belo Horizonte

\begin{tabular}{lccccc}
\hline & & \multicolumn{3}{c}{ Origem } \\
\cline { 3 - 6 } Regional de Belo Horizonte* & $\mathrm{n}^{1}$ & \multicolumn{2}{c}{ Original } & \multicolumn{2}{c}{ Manipulado } \\
& & Absoluto & Relativo & Absoluto & Relativo \\
\hline Leste & 12 & $0 / 6$ & $0 \%$ & $0 / 6$ & $0 \%$ \\
Norte & 12 & $0 / 6$ & $0 \%$ & $0 / 6$ & $0 \%$ \\
Oeste & 12 & $0 / 6$ & $0 \%$ & $0 / 6$ & $0 \%$ \\
Sul & 12 & $0 / 6$ & $0 \%$ & $0 / 6$ & $0 \%$ \\
\hline
\end{tabular}

*Regional Leste (Taquaril; Santa Efigênia; Centro; Sagrada Família). Regional Norte (Venda Nova; Céu Azul; Planalto). Regional Oeste (Pampulha; Coração Eucarístico; Caiçara). Regional Sul (Buritis; Barreiro; Mangabeiras). ${ }^{1}$ : N é o número de amostras coletadas.

A Tabela 1 representa os resultados para a frequência absoluta e relativas (\%) para casos positivos de pesquisa de Salmonella spp. queijo tipo mozzarella no qual verificou-se que 100\% destas amostras apresentaram ausência de Salmonella spp. em 10 gramas de queijo Mussarela.Na comparação sob diferentes tipos de processamento (original de fábrica ou manipulado pelo varejo) não foi evidenciado risco de contaminação em produtos fatiados. Não havendo também diferença entre as regionais leste, norte, oeste e sul de Belo Horizonte.

A ausência de Salmonella spp. também foi observada por Moreira \& Okura (2017) em queijo ricota, Silva et al., (2010) em queijo coalho, Pereira et al.(2016) em queijo artesanal serrano, Amorim et al. (2014) e Apolinário et al. (2014) em queijo minas.Conforme relatado por pesquisadores a ausência de Salmonella nas amostras analisadas pode ser devida a presença da microbiota autóctone, mais especificamente as bactérias lácticas, que tem a capacidade de restringir o crescimento de microorganismos patogênicos por competição e ou produção de moléculas antagônicas (Silva et al. 2010). A ausência pode ser explicada também pela realização de tratamentos térmicos na fabricação do queijo tipo Mussarela, bem como a pasteurização que tem por finalidade aumentar a segurança alimentar do queijo pela eliminação de bactérias patogênicas e diminuição do número de bactérias deterioradoras do leite (Paula et al., 2009).

Relatado por Oliveira (2005), outro ponto a se considerar são os parâmetros de temperatura e pH para o crescimento ótimo de Salmonella spp. sendo respectivamente de 35 a $37^{\circ} \mathrm{C}$ e 6,5 a 7,5 , os quais podem ter oscilado durante o processamento e estocagem do queijo, alterando no resultado das amostras.

Segundo Rezende et al. (2010), o resultado negativo para Salmonella spp. pode ser admitido, devido a sua baixa incidência no leite, dessa forma é preciso a existência de outra forma de contaminação, como contaminação no processamento ou rebanho doente.

Outro ponto que podemos destacar para a ausência da Salmonella spp. são o uso das boas práticas de higiene sanitária provavelmente seguidas pela fábrica, estabelecimentos escolhidos funcionários atuantes, já que segundo estudos estes são os principais vetores de contaminação dos alimentos nas fiambrerias. A utilização de fatiadoras exclusivas para a fiambrerias e a temperatura em que os alimentos são armazenados de $5^{\circ} \mathrm{C}$ nos balcões ou câmara e a retirada dos mesmos para fatiar não desencadeia variação significativa de temperatura pelo tempo de exposição e consequentemente o risco de contaminação desses produtos (Devides et al., 2014; Santos \& Hoffmann, 2010). 


\section{Conclusão}

Não foi observado a presença de Salmonella spp. em nenhum dos dois grupos de queijo Mussarela coletados, assim é possível inferir que os sistemas de produção e comercialização possuem a qualidade higiênico-sanitária necessária para que o produto seja negativo para Salmonella spp.

\section{Referências bibliográficas}

ABIQ. Associação Brasileira das Indústrias de Queijos. Estatísticas. São Paulo, SP. Disponível em http://www.abiq.com.br. Acesso em: 19/05/19.

Amorim, A. L. B. C., Couto, E. P., Santana, A. P., Ribeiro, J. L., \& Ferreira, M. de A. (2014). Avaliação da qualidade microbiológica de queijos do tipo Minas padrão de produção industrial, artesanal e informal. Revista do Instuto Adolfo Lutz, 73(4), 364-367. DOI: https://doi.org/10.18241/0073-98552014731628

Apolinário, T. C. C., Santos, G. S., \& Lavorato, J. A. A. (2014). Avaliação da qualidade microbiológica do queijo Minas frescak produzido por latícinios do estado de Minas Gerais. Revista do Instituto de Laticínios Cândido Tostes, 69(6), 433-442. DOI: https://doi.org/10.14295/2238-6416.v69i6.290

Birgel, D. B., Junior, E. H. B., Pogliani, F. C., Raimondo, R. F. S., Birgel, E. H., \& Araújo, W. P. (2009). Processo de secagem da glâncula mamária de bovinos da raça Holandesa: Avaliação das características microbiológicas da secreção láctea durante o período seco. Arquivos do Instituto Biológico, 76(4), 517-522.

Brasil, Instrução Normativa nº2, de 29 de dez. 2011, Diário Oficial Da União, Brasília, 30 de dezembro de 2011. Disponível em: 〈http://www.apcbrh.com.br/files/IN62.pdf〉. Acesso em: 20 nov. 2017.

Brasil. Ministério da Agricultura Pecuária e Abastecimento. Portaria n. 146, de 07 de março de 1996. Regulamentos Técnicos de Identidade e Qualidade dos Produtos Lácteos. Diário Oficial da União, Brasília, DF, Seção 1, p. 3977.

Brasil. Ministério da Agricultura, Pecuária e Abastecimento. Departamento de Inspeção de Produtos de Origem Animal. Instrução Normativa $n^{\circ}$ 62, de 26 de agosto de 2003. Oficializa os métodos analíticos oficiais para análises microbiológicas para controle de produtos de origem animal e água. Diário Oficial da República Federativa do Brasil, Brasília, 18 set. 2003. Seção 1, p. 14.

Brasil, Resolução - RDC n ${ }^{\circ} 12$, de 02 de janeiro de 2001. Aprova o "Regulamento técnico sobre padrões microbiológicos para alimentos" constante do anexo desta. Resolução. Órgão emissor: ANVISA - Agência Nacional de Vigilância Sanitária. Disponivel em: < http://portal.anvisa.gov.br/documents> Acesso em: 8 de janeiro de 2018.

Devides, G. G. G., Maffei, D. F., \& Catanozi, M. P. L. M. (2014). Perfil socioeconômico e profissional de manipuladores de alimentos e o impacto positivo de um curso de capacitação em boas práticas de fabricação. Brazilian Journal of Food Technology, 17, 166-176. DOI: https://doi.org/10.1590/bjft.2014.014

Freitas, M. F. L., Pinheiro Júnior, J. W., Stamford, T. L. M., Rabelo, S. S. A., Silva, D. R., da Silveira Filho, V. M., Santos, F. G. B., Sena, M. J., \& Mota, R. A. (2005). Perfil de sensibilidade antimicrobiana in vitro de Staphylococcus coagulase positivos isolados de leite de vacas com mastite no agreste do estado de pernambuco. Arquivo do Instituto Biológico de São Paulo, 72(2), 171-177.

Martins, E. (2001). Patrimônio de Minas. Jornal Estado de Minas, 44, 14-17.

Matsubara, M. T., Beloti, V., Tamanini, R., Fagnani, R., Silva, L. C. C., Monteiro, A. A., Battaglini, A. P. P., Ortolani, M. B. T., \& Barros, M. A. F. (2011). Boas práticas de ordenha para redução da contaminação microbiológica do leite no agreste Pernambucano. Semina: Ciências Agrárias, 32(1), 277-285. DOI: https://doi.org/10.5433/1679-0359.2011v32n1p277

Moreira, M. S., \& Okura, M. H. (2017). Qualidade microbiológica de ricotas comercializadas na região do triângulo mineiro e no interior do estado de São Paulo. Higiene Alimentar, 31(266/267), 96-101. 
Oliveira, R. P. de S. (2005). Condições microbiológicas e avaliação da pasteurização em amostras de leite comercializadas no município de Piracicaba-SP. Universidade de São Paulo. DOI: https://doi.org/10.11606/d.11.2005.tde-18072005-164621

Paula, J. C. J., Carvalho, A. F., \& Furtado, M. M. (2009). Princípios básicos de fabricação de queijo: do histórico à salga. Revista do Instituto de Laticínios Cândido Tostes, 64(367), 19-25.

Pereira, B. P., Schneider Neto, R., Pinto, A. T., \& Schmidt, V. (2016). Avaliação da qualidade microbiológica do queijo artesanal Serrano. Higiene Alimentar, 30(260/261), 130-134.

Rezende, P. H. L., Mendonça, E. P., Melo, R. T., Coelho, L. R., Monteiro, G. P., \& Rossi, D. A. (2010). Aspectos sanitários do queijo minas artesanal comercializado em feiras livres. Revista Do Instituto de Laticínios Cândido Tostes, 65(377), 36-42.

Santos, L. F., \& Lirio, V. S. (2014). Avaliação da adoção dos critérios da instrução normativa 62 pelos produtores de leite no município de Teixeira, MG. Revista Brasileira de Agropecuária Sustentável, 4(2), 32-40. DOI: https://doi.org/10.21206/rbas.v4i2.256

Santos, L. V. (2014). Avaliação das boas práticas de fabricação em agroindústrias do Distrito Federal (DF). In Nutrição: Vol. Monografia. Universidade de Brasília.

Santos, V. A. Q., \& Hoffmann, F. L. (2010). Avaliação das boas práticas de fabricação em linha de processamento de queijos Minas frescal e ricota. Revista do Instituto Adolfo Lutz, 67(387), 222228.

Silva, E. R. (2012). Perfil de sensibilidade antimicrobiana in vitro de Staphylococcus aureus isolado de mastite subclínica bovina. Revista Brasileira de Saúde e Produção Animal, 13(3), 701-711. DOI: https://doi.org/10.1590/s1519-99402012000300010

Silva, M. C. D., Moreno, I., \& Moraes, J. O. (2010). Influência dos procedimentos de fabricação nas características físico-químicas, sensoriais e microbiológicas de queijo de coalho. Revista do Instituto Adolfo Lutz, 69(2), 214-221.

Spilotro, D. (2003). Queijos de grife. Revista Diágolos Medicina, 4, 30-33.

Teixeira, L. V, \& Fonseca, L. M. (2008). Perfil físico-químico do soro de queijos mozarela e minaspadrão produzidos em várias regiões do estado de Minas Gerais. Arquivo Brasileiro de Medicina Veterinária e Zootecnia, 60(1), 243-250. DOI: https://doi.org/10.1590/s0102-09352008000100033

Vallin, V. M., Beloti, V., Battaglini, A. P. P., Tamanini, R., Fagnani, R., Angela, H. L., \& Silva, L. C. C. (2009). Melhoria da qualidade do leite a partir da implantação de boas práticas de higiene na ordenha em 19 municípios da região central do Paraná. Semina: Ciências Agrárias, 30(1), 181188. DOI: https://doi.org/10.5433/1679-0359.2009v30n1p181

Licenciamento: Este artigo é publicado na modalidade Acesso Aberto sob a licença Creative Commons Atribuição 4.0 (CC-BY 4.0), a qual permite uso irrestrito, distribuição, reprodução em qualquer meio, desde que o autor e a fonte sejam devidamente creditados. 